\title{
Effect of bone marrow-derived stem cells on chondrocytes from patients with osteoarthritis
}

\author{
QIANGZHI ZHANG ${ }^{1}$, YONG CHEN ${ }^{2}$, QIANG WANG ${ }^{1}$, CHAOYONG FANG $^{1}$, YU SUN $^{1}$, \\ TAO YUAN ${ }^{3}$, YUEBEI WANG $^{3}$, RONGNI BAO $^{3}$ and NINGJIAN ZHAO ${ }^{3}$
}

Departments of ${ }^{1}$ Orthopedics and ${ }^{2}$ Oncology, Subei People's Hospital of Jiangsu, Yangzhou, Jiangsu 225001;

${ }^{3}$ Department of Orthopedics, Jinling Hospital, Southern Medical University, Nanjing, Jiangsu 210002, P.R. China

Received May 26, 2014; Accepted March 3, 2015

DOI: $10.3892 / \mathrm{mmr} .2015 .4720$

\begin{abstract}
Increasing numbers of individuals are suffering from osteoarthritis every year, and the directed intra-articular injection of bone marrow stem cells has provided a promising treatment strategy for osteoarthritis. Although a number of studies have demonstrated that intra-articular injection of bone marrow stem cells produced desirable results, the mechanism underlying this effect has not been elucidated. In the current study, the effect of bone marrow stem cells on chondrocytes from patients with osteoarthritis was observed in a co-culture system. Human chondrocytes were obtained from patients with osteoarthritis who underwent surgical procedures and bone marrow stem cells were obtained from bone marrow aspirates, and then the chondrocytes were then cultured alone or cocultured with bone marrow stem cells in $0.4-\mu \mathrm{m}$ Transwell inserts. The differentiation and biological activity of chondrocytes in the culture system were measured, and the inflammatory factors and OA-associated markers were also measured. The results indicated that coculture with human bone marrow stem cells increases cell proliferation of chondrocytes and inhibits inflammatory activity in osteoarthritis.
\end{abstract}

\section{Introduction}

Osteoarthritis (OA) is a chronic age-related disease, it affects the majority of the adult population, and is characterized by the slowly progressive destruction of articular cartilage, and degeneration of ligaments and menisci, as well as hypertrophy of the joint capsule $(1,2)$. It is reported that changes in OA include decreased expression of chondrogenic markers [Aggrecan, collagen type II $\alpha 1$ (COL2A1) and SOX9], and enhanced expression of certain hypertrophic [matrix metallopeptidase

Correspondence to: Professor Ningjian Zhao, Department of Orthopedics, Jinling Hospital, Southern Medical University, 305 Zhongshan East Road, Nanjing, Jiangsu 210002, P.R. China E-mail: jianningzhao0525@126.com

Key words: osteoarthritis, chondrocytes, bone marrow stem cells, anti-inflammatory, coculture
(MMP13) and alkaline phosphatase] and fibroblastic [collagen I and collagen II (Col I, II and III, respectively)] markers $(3,4)$.

Current therapies for OA include a number of noninvasive (drug treatment and physical therapy) and invasive therapies (drilling, debridement, osteochondral transplantation, autologous perichondral and periosteal grafts, and autologous chondrocyte implantation) to relieve the symptoms $(5,6)$. Recently, stem cell based cell therapy was observed to provide a promising approach to OA treatment (7). Bone marrow-derived mesenchymal stem cells (BMSCs), which can be isolated from the bone marrow aspirate, and have multipotent differentiation potential (could differentiate into numerous tissues, such as bone, cartilage and fat), self-renewal capacity and immunomodulatory properties, has great potential for use in stem cell-based articular cartilage diseases (8).

Recent observations have shown that BMSCs also have shown desirable effects in the treatment of OA, probably via the secretion of bioactive trophic factors to exert potent anti-inflammatory, immunomodulatory, and antifibrotic effects $(9,10)$. Emadedin et al (11) reported that intra-articular injection of autologous bone marrow mesenchymal stem cells in patients with OA of the knee did not result in local or systemic adverse events after a one-year follow-up period. In addition, all patients were partly satisfied with the results of the study, and magnetic resonance images (MRI) at baseline and six months post-stem cell injection displayed an increase in cartilage thickness, extension of the repair tissue over the subchondral bone and a considerable decrease in the size of edematous subchondral patches in three out of six patients. In another case, Buda et al (12) demonstrated that in a one-step arthroscopic technique for the treatment of osteochondral lesions of the knee with bone-marrow-derived cells, the result of clinical inspection and MRI demonstrated that the mean international knee documentation committee score prior to surgery was $29.9 \pm 13.2$ and was $85.4 \pm 4.2$ at $29 \pm 4.1$ months $(\mathrm{P}<0.0005)$, while the knee injury and osteoarthritis outcome score before surgery was $35.1 \pm 11.9$ and was $87.3 \pm 7.3$ at $29 \pm 4.1$ months $(\mathrm{P}<0.0005)$. Control MRI and biopsy samples showed osteochondral regeneration of the lesion site. Though the desired result of directed intra-articular injection of bone marrow stem cells in the treatment of OA diseases was observed, the mechanism underlying this effect has not been reported. Therefore, in the current study, the potent anti-inflammatory, 
immunomodulatory, and antifibrotic effects of BMSCs on chondrocytes in OA in a coculture system were explored, as well as the proliferation of chondrocytes following coculture with BMSCs, in order to evaluate the potential application of BMSCs in the treatment of OA.

\section{Materials and methods}

This study was approved by the ethics committee of the Southern Medical University (Nanjing, China) and informed consent was obtained from all patients.

Cell isolation and culture. BMSCs were harvested from patients who underwent bone marrow aspiration. BMSCs were isolated by density-gradient centrifugation at $500 \mathrm{x} \mathrm{g}$ for $5 \mathrm{~min}$, resuspended and cultured in Dulbecco's modified Eagle's medium containing 10\% (v/v) fetal bovine serum (Hyclone, Logan, UT, USA) in 100-mm tissue culture flasks at $37^{\circ} \mathrm{C}$ in a $5 \% \mathrm{CO}_{2}$ humidified incubator. After $24 \mathrm{~h}$, the non-adherent cells were removed. After 10-14 days, adherent cells were trypsinized and sub-cultured.

Cartilage was harvested from patients with OA who underwent knee surgery, and chondrocytes were isolated and expanded as previously described (13). BMSCs and chondrocytes at passage 1 were used in this study.

Groupings. The chondrocytes were cultured in the six well plate, and BMSCs were seeded in the Transwell chamber (Corning Incorporated, Corning, NY, USA), with a $0.4-\mu \mathrm{m}$ porous membrane at the bottom to prevent cell migration. Cells were divided into the following groups: Experimental group, chondrocytes cocultured with BMSCs; and control group, chondrocytes cultured alone. In each group $1 \times 10^{4}$ BMSCs or chondrocytes at passage 1 were seeded. The culture medium was replaced every 2 days.

Cell proliferation. Chondrocyte proliferation was measured using cell counting kit-8 (CCK-8, Dojindo Molecular Technologies, Kumamoto, Japan) as previously described (14). NP cells $\left(10^{3}\right.$ cells; $\left.100 \mu \mathrm{l}\right)$ from the experimental and control groups were seeded into every well of the 96 -well plate. At different time points ( 1 day, 3 days, 5 days and 7 days), $10 \mu \mathrm{l}$ CCK-8 solution was added into each well. After another $2 \mathrm{~h}$, absorbance was measured spectrophotometrically at $450 \mathrm{~nm}$ using a Hitachi F-4500 fluorescence spectrophotometer (Hitachi, Ltd., Tokyo, Japan).

Protein release in the supernatant. Levels of major inflammatory proteins [interleukin (IL)-6, IL-8, CCL2/MCP-1, CCL3/MIP-1 $\alpha$, CCL5/RANTES, CXCL1/GRO $\alpha$ ], thrombospondin-1 (TSP-1) and tissue inhibitor of metalloproteinase-1 (TIMP-1) in the supernatant in each group at day 7 was quantified using ELISA kits (R\&D Systems, Minneapolis, MN, USA) according to the manufacturer's instructions. The test was performed in triplicate.

Differentiation characteristics of chondrocytes. Relative expression of cyclooygenase 2 (COX-2), prostaglandin E2 (PGE2), tumor necrosis factor (TNF)- $\alpha$, IL-1 $\beta$, IL-6, and IL-8 was measured in the two groups at day 7 to evaluate the

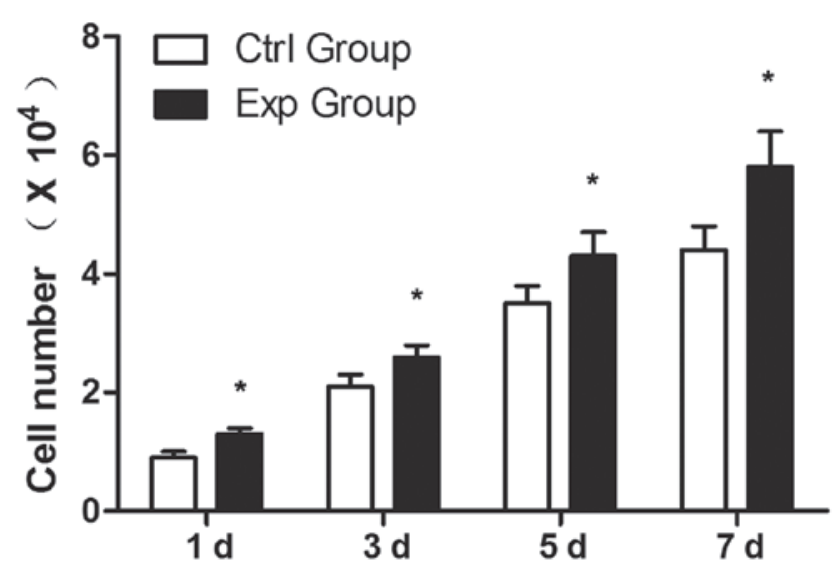

Figure 1. Proliferation of chondrocytes from patients with osteoarthritis The chondrocytes proliferated gradually in the 2 groups with the increased culture time, and there was a significant difference between the 2 groups at different time points $\left({ }^{*} \mathrm{P}<0.05\right)$.

anti-inflammatory effects of BMSCs on OA chondrocytes. Relative expression of type I collagen, type III collagen, MMP13, SOX-9, Aggrecan and type II collagen was measured in two groups at day 7 to evaluate differentiation characteristics of chondrocytes. RNA was extracted from chondrocytes in the two groups according to previously described methods (15), and reverse transcribed into cDNA according to the manufacturer's instructions. Reverse transcription-quantitative polymerase chain reaction (RT-qPCR) was used to evaluate the difference in gene expression in the two groups.

$R T-q P C R$. RT-qPCR was performed in a final reaction volume of $20 \mu \mathrm{l}$ containing $10 \mu \mathrm{l}$ of $2 \mathrm{X}$ SYBR Green PCR Universal Master mix (Applied Biosystems, Warrington, UK), $300 \mathrm{nM}$ of resuspended reference gene primer mix, $5 \mu$ of diluted cDNA and $4 \mu \mathrm{l}$ of RNase/DNase-free water. The primer sequences are shown in Table I. The thermal cycling conditions for RT-qPCR were as follows: $95^{\circ} \mathrm{C}$ for $10 \mathrm{~min}$ followed by 40 cycles of $95^{\circ} \mathrm{C}$ for $15 \mathrm{sec}$ and $60^{\circ} \mathrm{C}$ for $1 \mathrm{~min}$. All reactions were performed in duplicate using an ABI PRISM ${ }^{\circledR} 7000$ real-time PCR system (Applied Biosystems).

Statistical analysis. Differences in cell proliferation, gene expression and protein levels in each group were analyzed by one-way analysis of variance. Data were analyzed using SPSS version 16.0 (SPSS, Inc., Chicago, IL, USA). P<0.05 was considered to indicate a statistically significant difference.

\section{Results}

Cell proliferation. The cell yields in the two groups showed an increase in cell number with the increase in culture time (Fig. 1). There was a significant difference between the two groups at different time points, and greater cell proliferation in the experimental group than that in the control group $(\mathrm{P}<0.05)$.

Release of inflammatory protein in the supernatant. It has been demonstrated that chondrocytes secrete various inflammatory proteins in OA (16); thus, the release of inflammatory protein in the supernatant in two groups was 
Table I. Primer sequences for real-time polymerase chain reaction.

\begin{tabular}{|c|c|c|}
\hline Gene symbol & Primer & Product (bp) \\
\hline $\mathrm{COX}-2$ & & 382 \\
\hline Forward & 5'-ATAACCCCGCCAAAAGGGG-3' & \\
\hline Reverse & 5'-AGGAACAGCATGCAGGTAGC-3' & \\
\hline PGE-2 & & 116 \\
\hline Forward & 5'-GTCGTGTACCTGTCCAAGCA-3' & \\
\hline Reverse & 5'-GCGCTGGCGATGAACAAC-3' & \\
\hline IL-1 $\beta$ & & 177 \\
\hline Forward & 5'-CTGTCCTGCGTGTTGAAAG-3' & \\
\hline Reverse & 5'-TGCTTGAGAGGTGCTGATG-3' & \\
\hline IL-6 & & 184 \\
\hline Forward & 5'-TAGTGAGGAACAAGCCAGAG-3' & \\
\hline Reverse & 5'-GCGCAGAATGAGATGAGTTG-3' & \\
\hline IL-8 & & 153 \\
\hline Forward & 5'-CCAAACCTTTCCACCC-3' & \\
\hline Reverse & 5'-АСТТСТССАСААСССТ-3' & \\
\hline Sox-9 & & 281 \\
\hline Forward & 5'-AGGTGCTCAAAGGCTACGAC-3' & \\
\hline Reverse & 5'-GGCATTCCCTGAAGACCTGG-3' & \\
\hline COL2 $2 \alpha 1$ & & 373 \\
\hline Forward & 5'-CGAAAGGTCAGACGGGTGAA-3' & \\
\hline Reverse & 5'-GGCATTCCCTGAAGACCTGG-3' & \\
\hline Aggrecan & & 316 \\
\hline Forward & 5'-ACCTCACCATGCCTTCACTG-3' & \\
\hline Reverse & 5'-GCTCTCACCTTTCACCACGA-3' & \\
\hline COL $1 \alpha 2$ & & 70 \\
\hline Forward & 5'-TTCTCTAGAACTTTGCTGCTCA-3' & \\
\hline Reverse & 5'-AAGCATATCATTGGTCCAGGG-3' & \\
\hline $\operatorname{COL} 3 \alpha 1$ & & 354 \\
\hline Forward & 5'-CGCCCTCCTAATGGTCAAGG-3' & \\
\hline Reverse & 5'-AGGGCCTGAAGGACCAGCTT-3' & \\
\hline MMP13 & & 198 \\
\hline Forward & 5'-GACTTCCCAGGAATTGGTGA-3' & \\
\hline Reverse & 5'-TACCCCAAATGCTCTTCAGG-3' & \\
\hline GAPDH & & 353 \\
\hline Forward & 5'-CCACATCGCTGAGACACCAT-3' & \\
\hline Reverse & 5'-AAATGAGCCCCAGCCTTCTC-3' & \\
\hline
\end{tabular}

COX-2, cyclooxygenase-2; PGE-2, prostaglandin E2; IL, interleukin; COL, collagen; MMP, matrix metallopeptidase.

analyzed in the present study. The coculture system showed the inhibitory effect of inflammatory activity-related protein secretion. The results of ELISA demonstrated that the levels of inflammatory protein, such as IL-6, IL-8, CCL2/ MCP-1, CCL3/MIP-1 $\alpha$, CCL5/RANTES and CXCL1/GRO $\alpha$, decreased in the coculture system, which indicated that BMSCs exerted anti-inflammatory effects.

The concentration of IL-6, IL-8, CCL2/MCP-1, CCL3/MIP-1 $\alpha$, CCL5/RANTES and CXCL1/GRO $\alpha$ were measured (Fig. 2A-F). Production of IL-6 (9.00 ng/ml), IL-8 (4.10 ng/ml), CCL2/MCP-1 (4.50 ng/ml),
CCL3/MIP-1 $\alpha(3.6 \mathrm{ng} / \mathrm{ml})$, CCL5/RANTES $(25.60 \mathrm{ng} / \mathrm{ml})$ and CXCL1/GRO $\alpha(2.30 \mathrm{ng} / \mathrm{ml})$ in the experimental group were significantly reduced compared with the production of IL-6 (3.50 ng/ml), IL-8 (1.90 ng/ml), CCL2/MCP-1

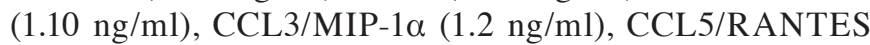
$(75.30 \mathrm{ng} / \mathrm{ml})$ and $\mathrm{CXCL} 1 / \mathrm{GRO} \alpha(4.50 \mathrm{ng} / \mathrm{ml})$ in the control group $(\mathrm{P}<0.05)$.

Expression of inflammatory genes in OA chondrocytes. A number of studies have reported that the expression of inflammatory genes in OA chondrocytes increased (16-18). The 
A

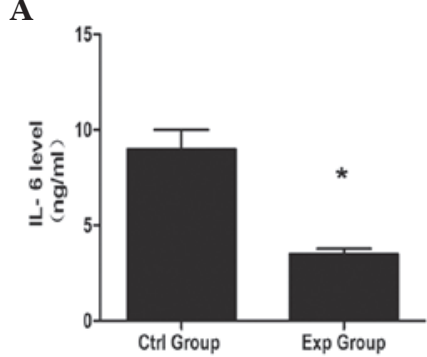

D

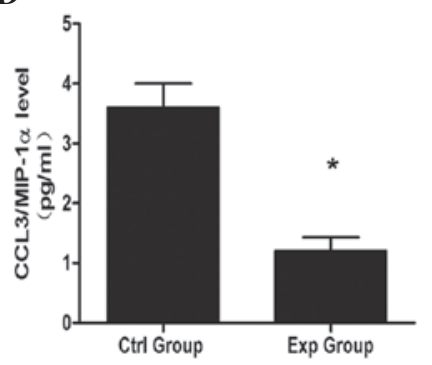

B

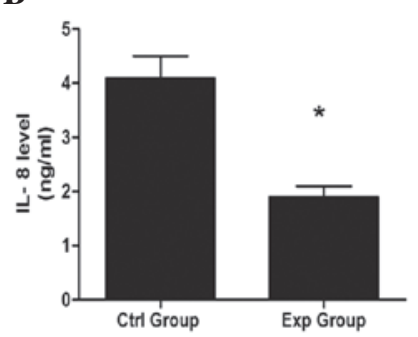

E

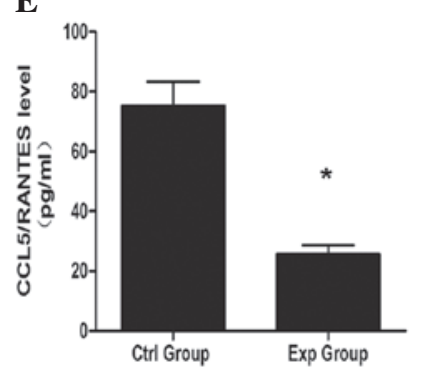

C

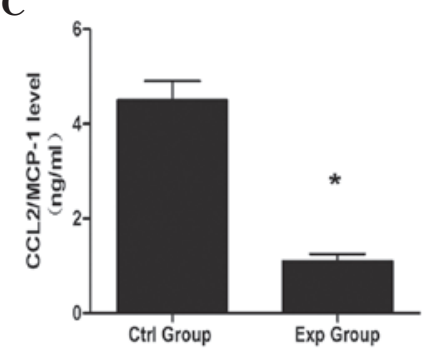

F

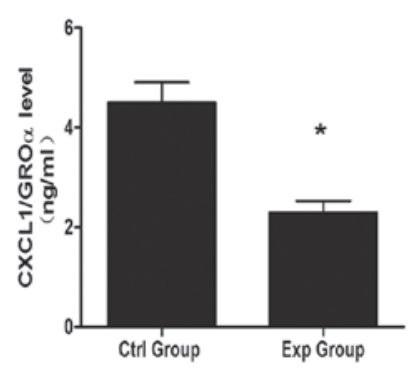

Figure 2. Level of inflammatory protein. These results showed the level of inflammatory proteins (A) IL-6, (B) IL-8, (C) CCL2/MCP-1, (D) CCL3/MIP-1 $\alpha$ (E) CCL5/RANTES and (F) CXCL1/GRO $\alpha$ in the experimental group is less than that in the control culture group, which indicated that BMSCs exerted the anti-inflammatory effect ( $\mathrm{P}<0.05)$. IL, interleukin.

A

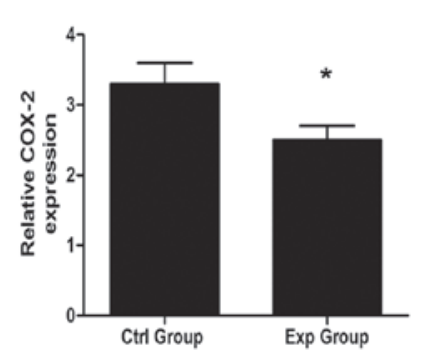

D

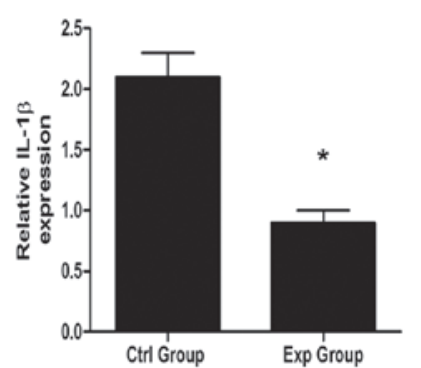

B

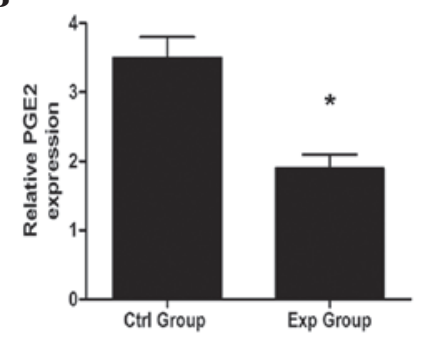

$\mathbf{E}$

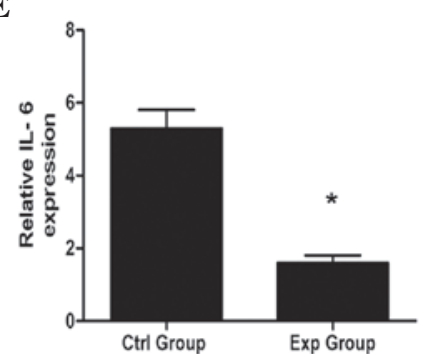

C

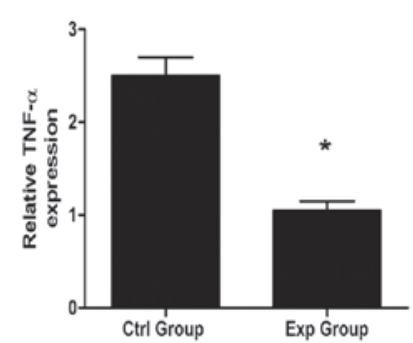

F

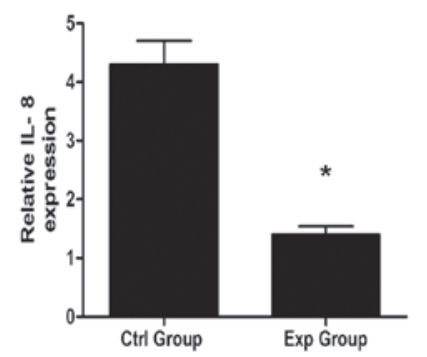

Figure 3. Expression of inflammatory genes. (A) COX-2, (B) PGE2, (C) TNF- $\alpha$, (D) IL-1 $\beta$, (E) IL-6 and (F) IL-8. There is a significant difference of the expression of inflammatory gene between 2 groups ( $\mathrm{P}<0.05$ ), and the expression of inflammatory gene in the experimental group is less than that in the control group. COX-2, cyclooxygenase 2, PGE2, prostaglandin E2; TNF- $\alpha$, tumor necrosis factor- $\alpha$; IL, interleukin.

co-culture system notably resulted in a reduction of COX-2, PEG2, TNF- $\alpha$, IL-6, IL-8 and IL-1 $\beta$ mRNA levels compared with the control group (Fig. 3; $\mathrm{P}<0.05$ ).

OA chondrocyte differentiation. OA chondrocytes become fibrous and undergo hypertrophy, which was demonstrated by upregulation of fibrotic (collagen type I) and hypertrophic (osteopontin, type X collagen and matrix Gla) genes. However, the expression of fibrotic and hypertrophic genes in the experimental group decreased after coculture with BMSCs, and there were significant differences between the two groups. The chondrogenic gene (type II collagen and aggrecan) expression increased in the experimental group, while the SOX-9 expression decreased after coculture (Fig. 4). The results indicated that BMSCs showed chondroprotective and antifibrotic effects, as well as antihypertrophic effects.

Release of TIMP-1 and TSP-1 in the supernatant. TSP-1 has been reported to have the ability to upregulate TIMP-1. TIMP-1 could inhibit the vascularization of chondrocytes, which suggests that TIMP-1 has chondroprotective effects. The levels of TSP- 1 and TIMP-1 were 63 and $735 \mathrm{pg} / \mathrm{ml}$ in the experimental group, while the level of TSP-1 and TIMP-1 was 42 and $598 \mathrm{pg} / \mathrm{ml}$ in the control, respectively (Fig. 5). 
A

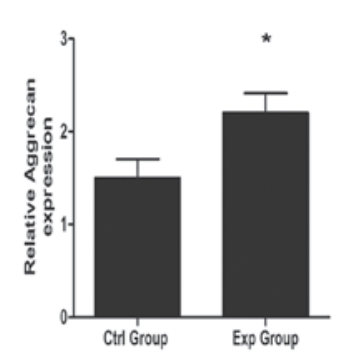

D

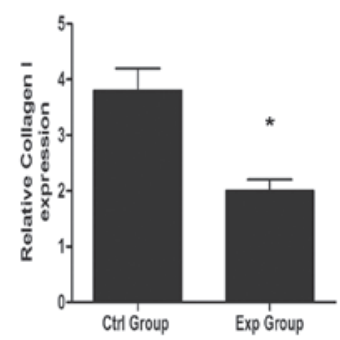

B

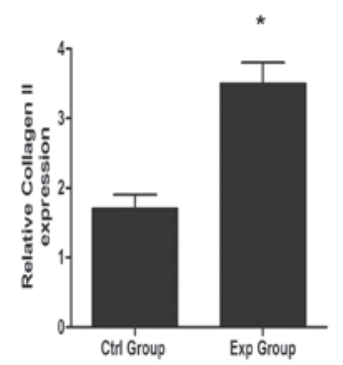

$\mathbf{E}$

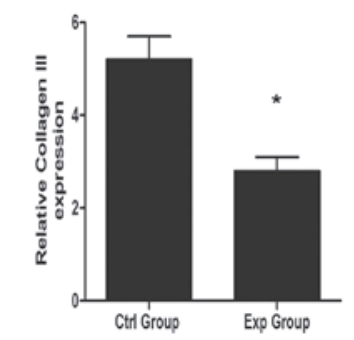

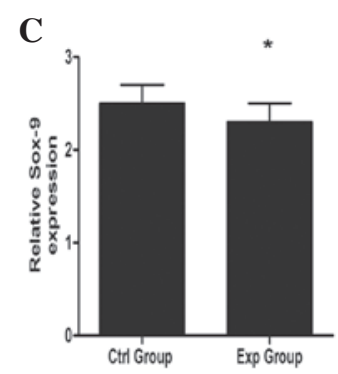

F

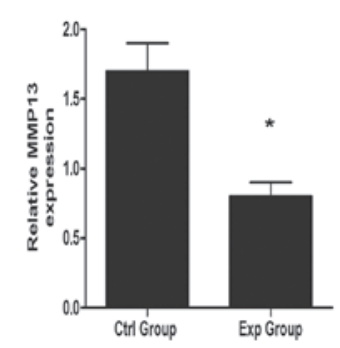

Figure 4. Differentiation of OA chondrocytes. (A) Aggrecan, (B) Collagen II, (C) SOX-9, (D) Collagen I, (E) Collagen III and (F) MMP-13. The expression of type II collagen and aggrecan the OA chondrocytes in co-culture groups is higher than that in the control group, while the gene expression of type I collagen, type III collagen and MMP13 in experimental group is less than that in the control group (" $\mathrm{P}<0.05)$. MP-13, matrix metallopeptidase 13; OA, osteoarthritis.

A

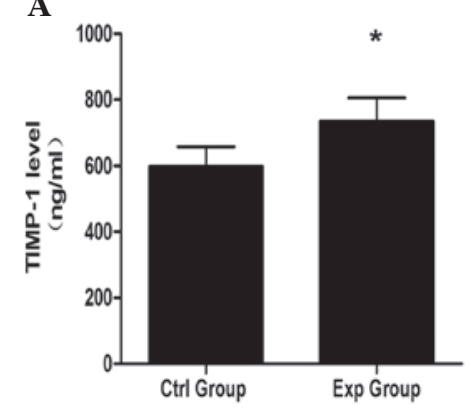

B

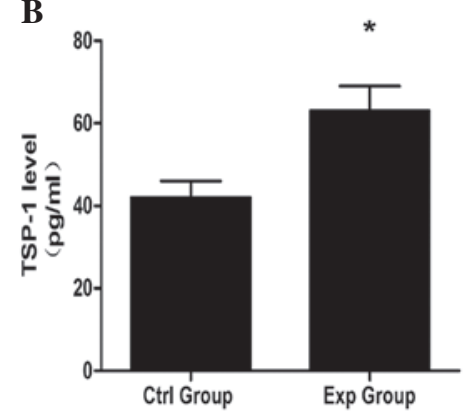

Figure 5. Level of growth factors. There is a significant difference in the concentration of protein between the 2 groups (P<0.05), and the level of (A) TIMP-1 and (B) TSP-1 in the supernatant in the experimental group is higher than that in the control group ( $\mathrm{P}<0.05)$. TIMP-1, tissue inhibitor of metalloproteinase-1; TSP-1, thrombospondin-1.

\section{Discussion}

Osteoarthritis (OA) is also termed chronic degenerative arthritis, degenerative joint disease or osteoarthrosis, and is characterized by progressive cartilage degeneration, subchondral bone impairment, the narrowing of the joint space, marginal osteophytosis, as well as loss of joint function (19). The common symptoms of osteoarthritis included joint pain, stiffness and a degree of loss of joint motion (20). It is reported that the inflammation is involved in the occurrence of OA, which promotes the ongoing joint degeneration (21). Recent studies have demonstrated that BMSCs have the potential for application in the treatment of OA as BMSCs have chondrogenic differentiation potential, and are also involved in the immunoregulation and tissue repair/regeneration by the secretion of various soluble factors. Firstly, BMSCs exhibit multilineage differentiation capacity and can develop into various cell types, including chondrocytes, osteoblasts and adipocytes (22). Secondly, BMSCs secrete a number of cytokines, such as hepatocyte growth factor, insulin-like growth factor-1, epidermal growth factor, keratinocyte growth factor, angiopoietin-1 and stromal derived factor-1, which possess a wide range of biological effects in the repair and regeneration of tissue (23). Therefore, in the present study the effect of BMSCs on chondrocytes from OA tissues was investigated, and the results indicated chondroprotective and antifibrotic effects, as well as antihypertrophic effects on the OA chondrocytes in a coculture system.

At first, the OA chondrocyte proliferation rate was analyzed in culture alone or coculture with BMSCs, and the results indicated that BMSCs significantly improved the cell proliferation rate, when compared with chondrocyte culture alone. It has been reported that BMSCs secrete different types of growth factors, including basic fibroblast growth factor (FGF-2), insulin-like growth factor 1 (IGF-1) and hepatocyte growth factor (HGF) (24). Among them, FGF-2 and IGF-1 have the capability to promote cell proliferation via the PI3-K pathway dependent signal pathway (25). Umeda et al (26) showed that BMSCs are more effective for increasing the proliferative capacity of nucleus pulposus cells via activation of rat nucleus pulposus cells by coculture with BMSCs. In the present study, the results of the CCK- 8 assay confirmed the effects of BMSCs promoting chondrocyte cell proliferation. 
The anti-inflammatory action of BMSCs on OA chondrocytes was investigated. It is well known that chondrocytes from patients with OA secrete various inflammatory cytokines and express inflammation activity-related genes (16). It has also been shown that certain OA inflammatory factors, such as IL-6, IL-8 and CXCL1/GRO $\alpha$, were involved in the progression of OA (27). The level of the inflammatory factors in the chondrocyte culture alone group and the coculture group were analyzed, a significant decrease in the release of inflammatory factors in the supernatant was observed after coculture with BMSCs, which indicated that BMSCs were anti-inflammatory in OA. BMSCs may inhibit macrophage activity and thereby suppress the production of catabolic mediators, such as IL-6, IL-8 and CXCL1/GRO $\alpha(16,28)$. The mRNA expression of the main OA inflammatory factors, such as COX-2, TGF- $\alpha$ and PEG2, were also measured to evaluate the anti-inflammatory effect. An increase in the gene expression level of COX-2, TNF- $\alpha$ and PEG2 were observed during inflammatory and catabolic processes. The results showed that the mRNA expression of the predominant $\mathrm{OA}$ inflammatory factors in the coculture group was less than that in the chondrocyte culture alone group.

In addition, the differentiation of chondrocytes was also investigated in the coculture system. It is reported that chondrocytes lost their original phenotype during OA progression, whereby the chondrocytes become ossified and vascularized (29). The results of the present study showed that the expression of aggrecan and collagen II increased after coculture with BMSCs, while the expression of SOX-9 decreased. Furthermore, the expression of hypertrophic (MMP13) and fibroblastic (Collagen I and III) markers of chondrocytes co-cultured with ASCs decreased, which demonstrated that BMSCs exerted an antifibrotic and antihypertrophic effect on the OA chondrocytes. TSP-1 and TIMP-1 may be important in the antifibrotic and antihypertrophic process, and it was demonstrated that the secretion of TSP-1 and TIMP-1 increased in the coculture system.

In conclusion, co-culture with human BMSCs inhibits inflammatory activity and increases cell proliferation of OA chondrocytes, as well as exhibiting an antifibrotic and antihypertrophic effect, which may occur via the secretion of various growth factors and cytokines from BMSCs.

\section{Acknowledgements}

This study was supported by the National Natural Science Foundation of China (grant no. 81000792).

\section{References}

1. Loeser RF: Age-related changes in the musculoskeletal system and the development of osteoarthritis. Clin Geriatr Med 26: 371-386, 2010.

2. Moran CJ, Pascual-Garrido C, Chubinskaya S, et al: Restoration of articular cartilage. J Bone Joint Surg Am 96: 336-344, 2014.

3. Mueller MB and Tuan RS: Functional characterization of hypertrophy in chondrogenesis of human mesenchymal stem cells. Arthritis Rheum 58: 1377-1388, 2008.

4. Maumus M, Manferdini C, Toupet K, et al: Adipose mesenchymal stem cells protect chondrocytes from degeneration associated with osteoarthritis. Stem Cell Res 11: 834-844, 2013

5. Falah M, Nierenberg G, Soudry M, Hayden M and Volpin G: Treatment of articular cartilage lesions of the knee. Int Orthop 34 621-630, 2010 .
6. Khashan M, Chechik O, Arbel R and Morag G: The treatment of focal chondral lesions of the knee. Harefuah 149: 542-546, 549, 2010 (In Hebrew).

7. Diekman BO and Guilak F: Stem cell-based therapies for osteoarthritis: challenges and opportunities. Curr Opin Rheumatol 25: 119-126, 2013.

8. Gupta PK, Das AK, Chullikana A and Majumdar AS: Mesenchymal stem cells for cartilage repair in osteoarthritis. Stem Cell Res Ther 3: 25, 2012.

9. Baraniak PR and McDevitt TC: Stem cell paracrine actions and tissue regeneration. Regen Med 5: 121-143, 2010.

10. Djouad F, Bouffi C, Ghannam S, Noël D and Jorgensen C: Mesenchymal stem cells: innovative therapeutic tools for rheumatic diseases. Nat Rev Rheumatol 5: 392-399, 2009.

11. Emadedin M, Aghdami N, Taghiyar L, et al: Intra-articular injection of autologous mesenchymal stem cells in six patients with knee osteoarthritis. Arch Iran Med 15: 422-428, 2012.

12. Buda R, Vannini F, Cavallo M, et al: One-step arthroscopic technique for the treatment of osteochondral lesions of the knee with bone-marrow-derived cells: three years results. Musculoskelet Surg 97: 145-151, 2013.

13. Xia Z, Duan X, Murray D, Triffitt JT and Price AJ: A method of isolating viable chondrocytes with proliferative capacity from cryopreserved human articular cartilage. Cell Tissue Bank 14: 267-276, 2013.

14. Xue K, Qi L, Zhou G and Liu K: A two-step method of constructing mature cartilage using bone marrow-derived mesenchymal stem cells. Cells Tissues Organs 197: 484-495, 2013.

15. Dell'accio F, De Bari C, Eltawil NM, Vanhummelen P, Pitzalis C: Identification of the molecular response of articular cartilage to injury, by microarray screening: Wnt-16 expression and signaling after injury and in osteoarthritis. Arthritis Rheum 58: 1410-1421, 2008.

16. Manferdini C, Maumus M, Gabusi E, et al: Adipose-derived mesenchymal stem cells exert antiinflammatory effects on chondrocytes and synoviocytes from osteoarthritis patients through prostaglandin E2. Arthritis Rheum 65: 1271-1281, 2013.

17. Goldring MB and Otero M: Inflammation in osteoarthritis. Curr Opin Rheumatol 23: 471-478, 2011.

18. Cho H, Walker A, Williams J and Hasty KA: Study of osteoarthritis treatment with anti-inflammatory drugs: Cyclooxygenase-2 inhibitor and steroids. Biomed Res Int 2015, 2015.

19. Frisbie DD, Kisiday JD, Kawcak CE, Werpy NM and McIlwraith CW: Evaluation of adipose-derived stromal vascular fraction or bone marrow-derived mesenchymal stem cells for treatment of osteoarthritis. J Orthop Res 27: 1675-1680, 2009.

20. Strassle BW, Mark L, Leventhal L, et al: Inhibition of osteoclasts prevents cartilage loss and pain in a rat model of degenerative joint disease. Osteoarthritis Cartilage 18: 1319-1328, 2010.

21. Vincent KR, Conrad BP, Fregly BJ and Vincent HK: The pathophysiology of osteoarthritis: a mechanical perspective on the knee joint. PM R 4 (Suppl 5): 3-9, 2012.

22. Derubeis AR and Cancedda R: Bone marrow stromal cells (BMSCs) in bone engineering: limitations and recent advances. Ann Biomed Eng 32: 160-165, 2004.

23. Caplan AI and Dennis JE: Mesenchymal stem cells as trophic mediators. J Cell Biochem 98: 1076-1084, 2006.

24. Boomsma RA and Geenen DL: Mesenchymal stem cells secrete multiple cytokines that promote angiogenesis and have contrasting effects on chemotaxis and apoptosis. PLoS One 7: e35685, 2012.

25. Weber GF and Menko AS: Phosphatidylinositol 3-kinase is necessary for lens fiber cell differentiation and survival. Invest Ophthalmol Vis Sci 47: 4490-4499, 2006.

26. Umeda M, Kushida T, Sasai K, et al: Activation of rat nucleus pulposus cells by coculture with whole bone marrow cells collected by the perfusion method. J Orthop Res 27: 222-228, 2009.

27. Merz D, Liu R, Johnson K and Terkeltaub R: IL-8/CXCL8 and growth-related oncogene alpha/CXCL1 induce chondrocyte hypertrophic differentiation. J Immunol 171: 4406-4415, 2003.

28. Chen HW, Chen HY, Wang LT, et al: Mesenchymal stem cells tune the development of monocyte-derived dendritic cells toward a myeloid-derived suppressive phenotype through growth-regulated oncogene chemokines. J Immunol 190: 5065-5077, 2013

29. van der Kraan PM and van den Berg WB: Chondrocyte hypertrophy and osteoarthritis: role in initiation and progression of cartilage degeneration? Osteoarthritis Cartilage 20: 223-232, 2012. 